\title{
Gershom Scholem, Leo Strauss, Cabale et Philosophie. Correspondance 1933-1935
}

Paris, Éditions de l'Éclat, 2006, 177 p.

\section{Michael Löwy}

\section{(2) OpenEdition}

\section{Journals}

Édition électronique

URL : http://journals.openedition.org/assr/4043

DOI : $10.4000 /$ assr.4043

ISSN : $1777-5825$

Éditeur

Éditions de l'EHESS

Édition imprimée

Date de publication : 1 décembre 2006

Pagination : 115-283

ISBN : 2-7132-2124-2

ISSN : 0335-5985

\section{Référence électronique}

Michael Löwy, "Gershom Scholem, Leo Strauss, Cabale et Philosophie. Correspondance 1933-1935 »,

Archives de sciences sociales des religions [En ligne], 136 | octobre - décembre 2006, document 136-97, mis en ligne le 14 février 2007, consulté le 21 septembre 2020. URL : http://journals.openedition.org/ assr/4043 ; DOI : https://doi.org/10.4000/assr.4043

Ce document a été généré automatiquement le 21 septembre 2020.

(c) Archives de sciences sociales des religions 


\title{
Gershom Scholem, Leo Strauss, Cabale et Philosophie. Correspondance
}

\section{3-1935}

Paris, Éditions de l'Éclat, 2006, 177 p.

\author{
Michael Löwy
}

1 Cette correspondance entre deux éminents représentants de la culture judéoallemande illustre bien la diversité de cet univers culturel aujourd'hui disparu. Les deux avaient beaucoup en commun: la langue allemande, l'adhésion au sionisme, l'intérêt pour la religion, une critique acerbe des Lumières modernes. Et pourtant, comme le montre bien Olivier Sedeyn dans sa remarquable introduction au volume, leur rapport au judaïsme reste profondément différent, ce qui explique pourquoi, malgré leurs rapports chaleureux, ils ne citent presque jamais les travaux de l'autre dans leurs écrits...

2 Dès le début de leurs échanges, Leo Strauss se rend compte de leur désaccord, qui résulte non seulement d'une différence de méthode - "vous êtes historien de la religion, moi je suis historien de la philosophie »-mais de l'impossibilité pour celui-ci de pénétrer dans l'univers de la mystique juive qui est au centre de l'intérêt de Scholem. "Je ne comprends pas la Kabbale», "Je ne comprends pas la mystique », "Je suis congénitalement incapable de vous suivre » : cet aveu revient, comme un leitmotiv, dans ses lettres.

3 Certes, Strauss s'intéresse beaucoup à la religion juive, notamment dans sa dimension philosophique, «rationaliste médiévale»: Maimonide. Souvent dans la correspondance, il oppose Maimonide - le Rambam - à la cabale et au messianisme d'un Isaac Luria : « je n'ai jamais été un partisan du messianisme et je ne le deviendrai pas ». Son opposition à l'orthodoxie religieuse juive est assez catégorique; dans une lettre à Scholem, datée de 1934 - il se trouve à ce moment en exil en Angleterre - Strauss lui adresse cet appel et cet aveu: "aidez-moi à trouver un poste quelque part dans le monde, c'est-à-dire en Angleterre ou aux États Unis (...) je ne suis pas un juif orthodoxe, et ma candidature ne saurait être envisagée par un institut orthodoxe (...) je ne peux, 
cela va sans dire, faire aucune concession sur ce point». Scholem s'efforce de lui trouver un poste à Jérusalem, mais dans une lettre à Walter Benjamin il écrit, sur Strauss : «je me suis donné beaucoup de mal afin qu'il soit nommé à Jérusalem », mais son livre sur Maimonide, « avec un courage admirable pour un auteur que tous doivent considérer comme candidat pour Jérusalem», commence par "une profession d'athéisme ouverte et argumentée de manière détaillée, bien que complètement folle, déclarant que l'athéisme est le principal mot d'ordre juif !... J'admire cette moralité et je déplore le suicide évidemment conscient et délibéré d'un esprit aussi brillant». Strauss n'aura pas le poste à Jérusalem, mais obtient une bourse Rockefeller - grâce à une lettre de recommandation de... Carl Schmitt - pour les États-Unis où il fera une brillante carrière universitaire.

4 La correspondance des deux va s'interrompre pour une longue période, de 1935 à 1950, pour ne reprendre qu'après la visite aux États-Unis de Scholem (1949) qui lui permettra de nouer des liens personnels directs avec Leo Strauss. La question du "mythe" revient souvent dans leurs échanges : pourquoi employez-vous ce terme, à propos de la cabale, demande avec insistance le philosophe. Parce que, répond Scholem, «je ne vois pas de meilleur terme pour caractériser la structure de pensée de Luria ». Le fonds de leur désaccord est lucidement formulé par Strauss dans une lettre de 1960: «Nous sommes d'accord que le rationalisme moderne (...) est au bout du rouleau. J'avoue que je ne suis pas sûr que vous soyez complètement dépourvu de romantisme. J'entends par romantisme l'opinion selon laquelle la compréhension pré-rationaliste (...) est supérieure à la compréhension moderne (...) ». En dernière analyse, Strauss reste un rationaliste, même s'il préfère le rationalisme grec de Platon, ou celui, juif, de Maimonide, aux Lumières modernes qui commencent avec Spinoza. Scholem, par contre, est un historien d'inspiration romantique, ce qui ne signifie pas une préférence pour la "compréhension pré-rationaliste ", mais un intérêt passionné pour celle-ci et donc la capacité de comprendre - au sens fort - la mystique, la cabale et le messianisme. Comment expliquer cela à son interlocuteur? Dans sa réponse Scholem constate, avec regret: « Au sujet de nos conceptions du romantisme et du mythe, nous ne pourrons pas nous accorder facilement par écrit ».

5 Un autre sujet de malentendu entre eux est le rapport à la pensée de Martin Buber. Leo Strauss, fidèle à son rationalisme anti-romantique, dénie tout intérêt à cette œuvre et à son auteur, qu'il qualifie de " parfumeur »; il croit que Scholem partage son avis, mais lorsque celui-ci lui envoie, en 1963, un article sur Buber - certes critique, mais assez nuancé - il est déçu et se plaint de «votre admiration pour Buber ». Quelques années plus tard, il reconnait, un peu à contre cœur: «Vous avez réussi ce que personne n'avait réussi jusqu'ici : éveiller en moi un certain intérêt pour Buber ».

6 Le désaccord est aussi assez évident au sujet de Walter Benjamin. Dans une première lettre, de 1965, Strauss avoue : «j'ai très mal compris votre article sur Benjamin ». Cinq ans plus tard, ayant lu la correspondance de celui-ci, il pense - à tort ! - avoir compris : "Ce que Benjamin cherchait vraiment, Heidegger l'a dit d'une manière beaucoup plus radicale et claire, à mon avis, et peut-être poussée à l'absurde ».

7 Cette correspondance témoigne de ces nombreux malentendus mais aussi d'une certaine communauté d'esprit et surtout d'une volonté de dialogue, malgré l'océan - au propre et au figuré - qui les sépare. 